\title{
Análise do NDVI/NOAA em cana-de-açúcar e Mata Atlântica no litoral norte de Pernambuco, Brasil
}

\author{
Abdoral de A. Lucas ${ }^{1}$ \& Carlos A. B. Schuler ${ }^{1}$
}

\begin{abstract}
RESUMO
Neste trabalho se realizou a análise espaço-temporal do NDVI (Índice de Vegetação da Diferença Normalizada) na cultura da cana-de-açúcar, considerando-se a idade fenológica e a influência da precipitação pluvial dos meses atual e anterior relativos à safra 2003/2004. A metodologia foi aplicada em três áreas, ou seja, duas com cana-de-açúcar e uma de Mata Atlântica; cada área representa um pixel do satélite NOAA (National Oceanic and Atmospheric Administration). Os pontos amostrais P1 e P2 indicam áreas com plantio de cana e o ponto P3, um fragmento de Mata Atlântica, todos localizados na Usina São José, no Litoral Norte de Pernambuco. O estádio fenológico da cana-de-açúcar foi relacionado com o NDVI e com a precipitação referente a 6 épocas do ciclo da cultura. Aplicou-se, para a análise espaço-temporal, o índice de vegetação da diferença normalizada, utilizando-se imagens do sensor AVHRR (Advanced Very High Resolution Radiometric/NOAA-16. Os resultados mostraram maior influência da precipitação do mês anterior no comportamento do NDVI. Em relação ao ciclo da cultura, o estádio de desenvolvimento acompanha a evolução do NDVI, ou seja, na medida em que ocorre um ganho de biomassa, aumenta o valor do NDVI e ele começa, então, a decair quando se inicia o estádio de maturação, a partir do sétimo mês após o corte.
\end{abstract}

Palavras-chave: resolução temporal, sensor AVHRR, estádio fenológico

\section{Analysis of NDVI/NOAA in sugar cane and Atlantic Forest in the north of Pernambuco state, Brazil}

\begin{abstract}
This paper accomplished a space-temporal analysis of NDVI (Normalized Difference Vegetation Index) in sugar cane crop, considering the phenological stage and the influence of pluvial precipitation of the current and previous month of 2003/2004 harvest. The methodology was applied in three areas, two with sugar cane and one of Atlantic Forest. Each area represents a pixel of the NOAA (National Oceanic and Atmospheric Administration) satellite. Points P1 and P2 represent areas with sugar cane and point P3 a fragment of Atlantic Forest, all located at the Usina São José, in North of Pernambuco State. The phenological stage of sugar cane was related with NDVI and the precipitation of six periods of the crop cycle. For the space-temporaly analysis, the normalized difference vegetation index was applied, using images of sensor AVHRR (Advanced Very High Resolution Radiometric)/NOAA-16. The results showed a larger influence of precipitation of the previous month in the behavior of NDVI. In relation to the crop cycle, the development stage followed the evolution of NDVI, in other words, as biomass increases, the value of NDVI increases, and it begins to decrease when the maturation stage begins, starting from the seventh month after cutting.
\end{abstract}

Key words: temporal resolution, AVHRR sensor, phenological stage 


\section{INTRODUÇÃO}

A cultura da cana-de-açúcar estabeleceu, no Brasil, ciclos de grande importância econômica e social, haja vista tratarse de fonte de energia renovável e gerar divisas para o País. É cultivado no Norte-Nordeste, Sudeste e Centro-Sul, o que permite dois períodos de safra, de abril a novembro e de setembro a abril.

No plano da produção, o setor sucroalcooleiro representa 1,2\% do PIB nacional, além de ser responsável por um faturamento anual de US\$ 8,7 bilhões, gerando 1 milhão de empregos diretos (Pontes et al., 2005). Com esses números, o Brasil se situa como o maior produtor de cana-de-açúcar do mundo, seguido da Índia e da Austrália; na média, 55\% da cana moída internamente geram álcool e 45\%, açúcar (Fortes, 2003).

A previsão de safras por meio de sensoriamento remoto tem, como finalidade, a interpretação automática, o monitoramento contínuo e atualizado de grandes áreas agrícolas, além do menor custo e menor tempo para as estimativas. A agilidade e a disponibilidade de informações precisas podem facilitar a elaboração de estratégias referentes ao armazenamento e dar suporte às decisões. O estudo de fenologia da cultura constitui um parâmetro importante para a avaliação do desenvolvimento e manejo da cana-de-açúcar, através do NDVI associados à precipitação, dando suporte ao monitoramento da biomassa.

Desta forma, é conveniente monitorar a cultura da canade-açúcar, através de sensores de alta resolução temporal como, por exemplo, o AVHRR, que vem sendo muito utilizado no monitoramento da vegetação em escala regional e global e no monitoramento de culturas agrícolas através do crescimento de biomassa. Com este trabalho, se objetivou acompanhar e avaliar o crescimento fenológico durante um ciclo da cultura, associar o comportamento dos valores de NDVI temporais com o estádio de desenvolvimento em função da idade durante o ciclo, gerar gráficos descrevendo o comportamento do NDVI na cana-de-açúcar durante esse ciclo e correlacionar a resposta do NDVI com a precipitação do mês anterior e atual.

\section{MATERIAL E MÉTODOS}

\section{Área de estudo}

O trabalho foi desenvolvido na Usina São José, com sede no Município de Igarassu, Litoral Norte de Pernambuco (Figura 1); a área da usina é de aproximadamente $250 \mathrm{~km}^{2}$, ocupada espacialmente pela cultura da cana-de-açúcar e Mata Atlântica do tipo Floresta Ombrófila Densa, nativa no local; esta região se destaca na produção de cana-de-açúcar, em virtude de apresentar altos índices pluviométricos, em torno de $1300 \mathrm{~mm}$ por ano, com as chuvas se concentrando entre os meses de maio e junho (Barbosa, 1998), ocorrendo também um período crítico de três meses sem chuvas, de outubro a dezembro (Koffler et al., 1986).

Na área foram estabelecidos três pontos amostrais: o ponto amostral P1 se localiza sobre o Latossolo Vermelho Ama- relo Distrófico, que apresenta as seguintes características: relevo plano a suave-ondulado, textura argilo/argila arenoso, boa profundidade efetiva, drenagem interna boa e ausência de pedregosidade; para o ponto amostral P2 tem-se solo do tipo Podzólico Vermelho Amarelo; são solos que apresentam algumas limitações, como: relevo acentuado, prejudicando a motomecanização das operações agrícolas, alta susceptibilidade à erosão, com drenagem interna de boa a moderada. Os pontos P1 e P2 representam áreas de canade-açúcar e o ponto P3, um fragmento de Mata Atlântica, com suas respectivas coordenadas: $\mathrm{N}=9131079,97 \mathrm{~m}, \mathrm{E}$ $=278030,36 \mathrm{~m} ; \mathrm{N}=9136100,18 \mathrm{~m}, \mathrm{E}=273903,25 \mathrm{~m} ; \mathrm{N}$ $=9139830,76 \mathrm{~m}, \mathrm{E}=278717,10 \mathrm{~m}$, que serviram para identificar seus correspondentes pixels na imagem e análise do comportamento do NDVI.

\section{Imagem AVHRR/NOAA}

Para execução dos objetivos propostos, utilizaram-se mosaicos de imagens mensais de NDVI dos satélites AVHRR/ NOAA, em que os efeitos atmosféricos são atenuados pela composição dos valores máximos de NDVI, no período de um mês.

As imagens foram adquiridas pela Estação de Recepção de Imagens de Satélites - RRS (Recife Receiving Station), localizada no GEOSERE - Laboratório de Geoprocessamento e Sensoriamento Remoto da UFRPE - Universidade Federal Rural de Pernambuco. As imagens são captadas pela RRS em tempo real, através do sistema HRPT (High Resolution Picture Transmission) captadas em resolução máxima, no momento da passagem do satélite, durante o período em que o mesmo estiver na área de rastreio da antena, processo este que ocorre de forma automática necessitando, no entanto, de um monitoramento contínuo para detecção e correção de possíveis erros.

Obteve-se, para cada mês analisado neste trabalho, a Composição de Máximo Valor - CMV (Ferreira, 2004). As imagens utilizadas foram do NOAA - 16 e a passagem realizada em torno das $14 \mathrm{~h}$, devido a área teste se encontrar mais próxima do nadir, obtendo-se resolução espacial em torno de $1 \mathrm{~km}$. O GEOSERE capta as imagens e as processa com algoritmos existentes no programa TeraScan desenvolvidos para este satélite. Após a geração das imagens mensais, procedeu-se à extração dos valores de NDVI utilizando-se o valor médio, máximo e mínimo de uma janela de amostragem de $3 \times 3$ pixels cujo pixel central corresponde a cada um dos três pontos amostrais em cada local. Os valores de NDVI da janela de amostragem foram expressos em forma de gráfico como função do tempo obtendo-se, assim, os perfis espectrais de NDVI máximos mensais.

\section{Padronização dos dados AVHRR/NOAA}

A imagem NDVI/NOAA é padronizada para uma amplitude de $-0,097$ a 0,70. Nas imagens NDVI obtidas a partir do sensor AVHRR, a normalização reduz de 10 a 30\% o efeito da degradação da calibração do satélite para determinada banda e entre 0 e $6 \%$ para o próprio índice (Kaufman \& Holben, 1993); desta forma, são reduzidos significativamente os efeitos da dependência angular da 
A.

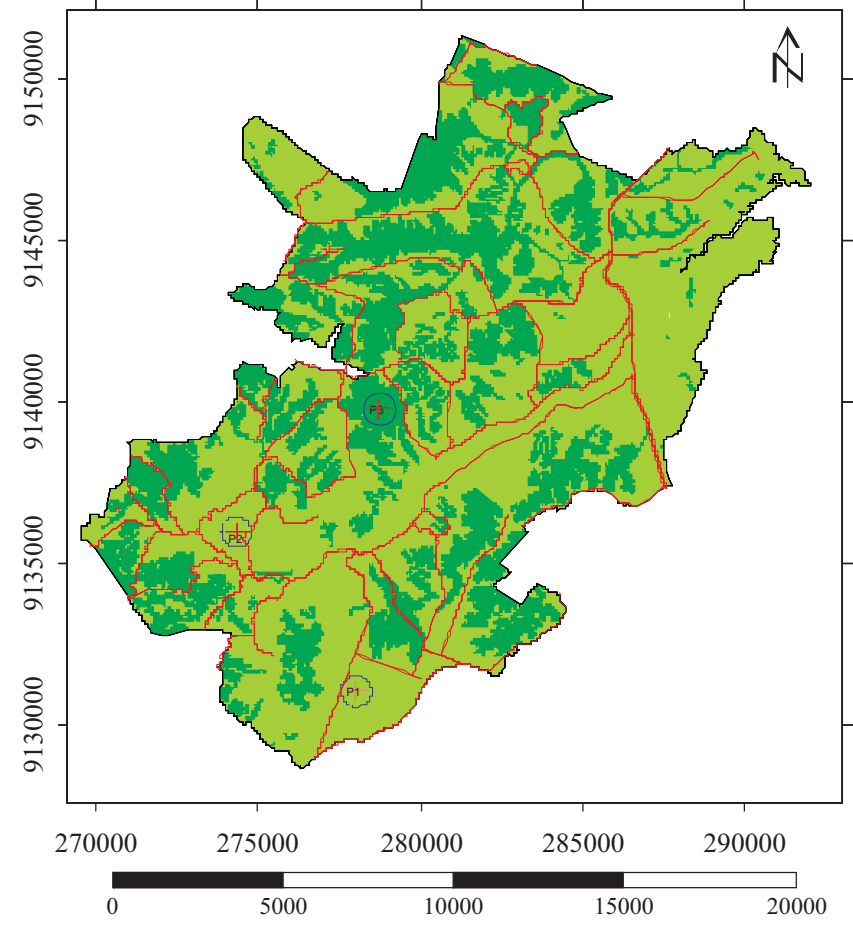

LEGENDA
C.

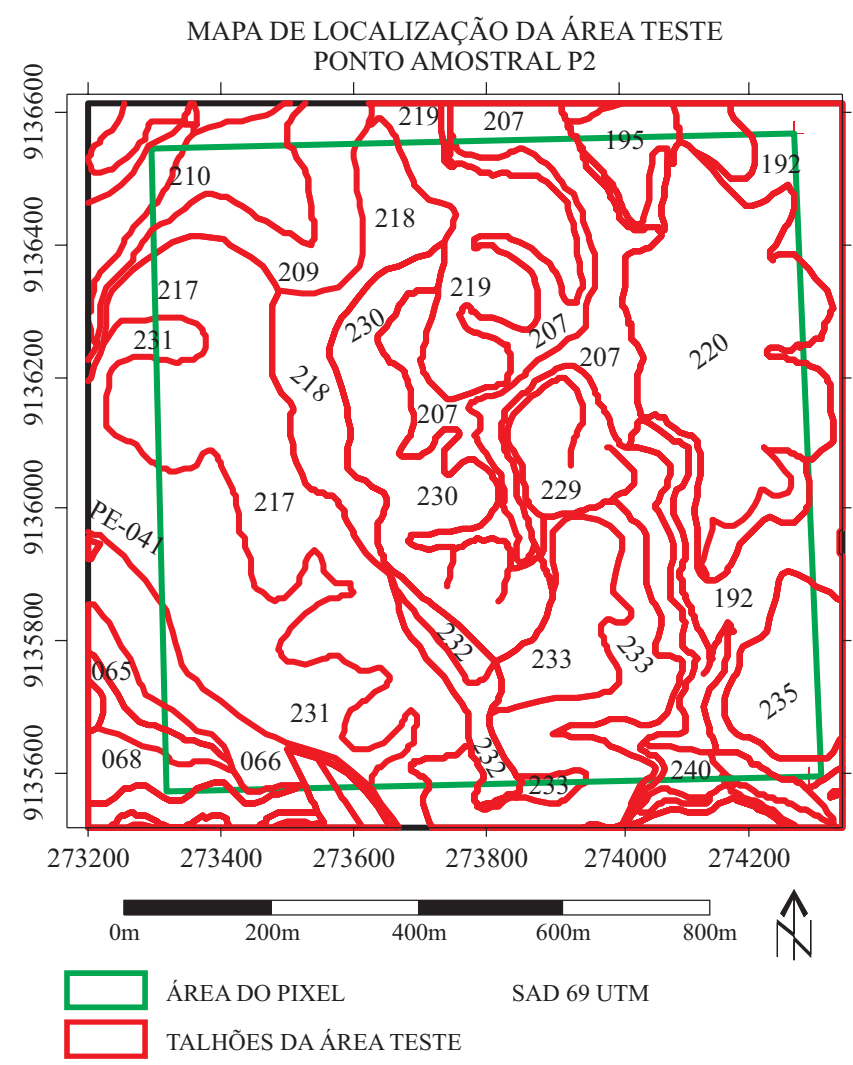

B.

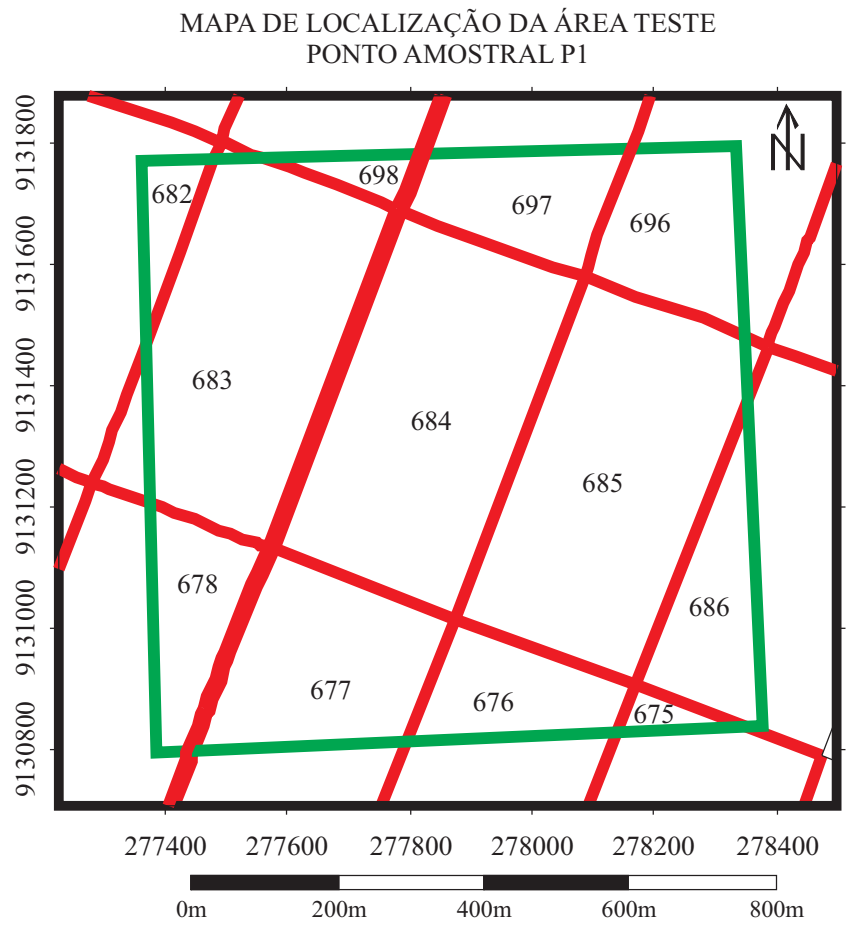

TALHÕES DA ÁREA TESTE

SAD 69 UTM
D.

MAPA DE LOCALIZAČ̃̃O DA ÁREA TESTE PONTO AMOSTRAL P3

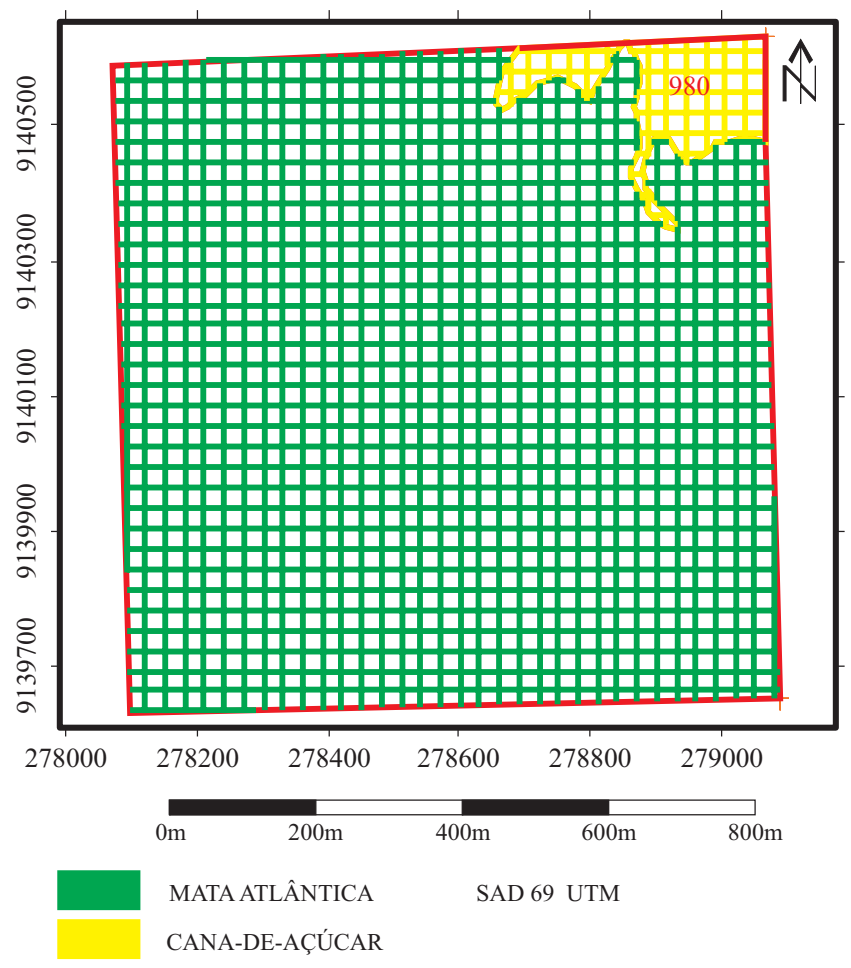

Figura 1. (A) Mapa de uso do solo com indicação dos pontos amostrais; (B) Área do pixel do Ponto P1 e localização dos talhões; (C) Área do pixel do Ponto P2 e localização dos talhões e (D) Área do pixel do Ponto P3. OBS.: coordenadas em m 
reflectância bidirecional da superfície e da atmosfera (Tanré et al., 1992). Na teoria, os valores de NDVI oscilam em um intervalo de $-1,0$ e $+1,0$, embora na prática esses valores oscilem entre -0,1 e +0,7 (Goward et al., 1985).

Para as imagens processadas no GEOSERE, o algoritmo de padronização do TeraScan do NDVI, estabelece uma variação entre $-0,097$ e $+0,70$.

\section{Dados meteorológicos da usina}

A estação meteorológica se localiza na área da Usina, com coordenadas UTM N = 9.135.714,88 m E = 279.558,55 m, no sistema de referência geodésico SAD 69. A Tabela 1 mostra a pluviometria bimestral, durante um ano, verificada na área.

Tabela 1. Pluviometria bimestral na Usina São José

\begin{tabular}{ccc}
\hline Mês & Precipitação Atual $(\mathbf{m m})$ & Precipitação Anterior $(\mathbf{m m})$ \\
\hline Nov/03 & 17,2 & 53,6 \\
\hline Jan/04 & 453,4 & 35,0 \\
\hline Mar/04 & 209,9 & 206,4 \\
\hline Mai/04 & 278,8 & 293,0 \\
\hline Jul/04 & 279,7 & 585,2 \\
\hline Set/04 & 53,8 & 97,2 \\
Nov/04 & 26,2 & 25,9 \\
\hline
\end{tabular}

Fonte: Usina São José

\section{RESULTADOS E DISCUSSÃO}

Observa-se, na Figura 2, que o comportamento do NDVI é semelhante ao da precipitação, atingindo o valor máximo no mês de julho, para o ponto P1, e começando a diminuir a partir desse mês; percebe-se também que precipitações superiores ao normal não têm grande influência no comportamento do NDVI, como é visto para o valor do NDVI do mês de julho, de 0,6066, e a precipitação de 585,2 mm para o mês anterior, em comparação com o mês de maio, que registrou um NDVI de 0,5372 e uma precipitação do mês anterior de 293 mm.

Com relação ao ponto P2 (Figura 2), e apesar de uma precipitação bastante alta na análise do mês de julho, não

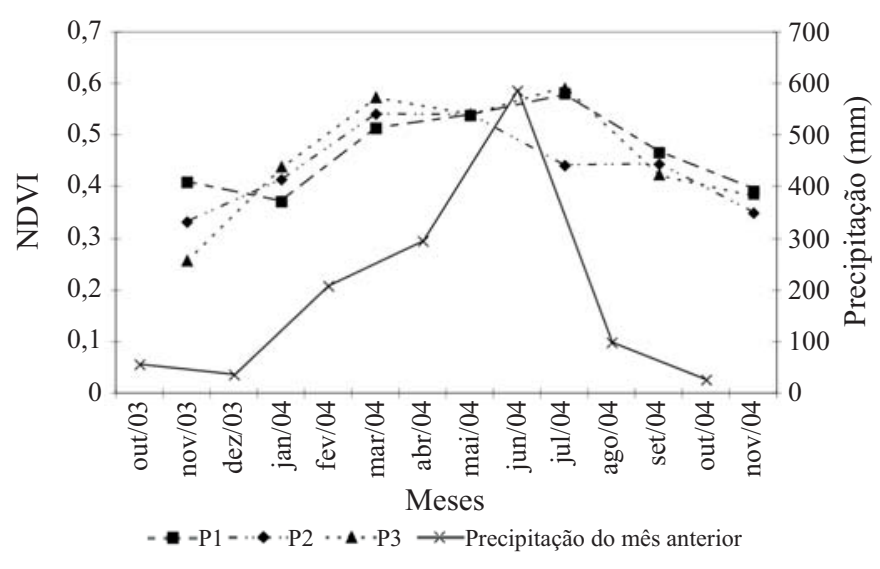

Figura 2. Gráfico do comportamento do NDVI e precipitação do mês anterior para os três pontos amostrais ocorreu influência no NDVI, caso em que o NDVI diminuiu em virtude de alguns talhões terem sido colhidos, somando uma área de 29,25 ha, representando 28,88\% da área total. No início do ciclo da cultura ocorre tendência de aumento do NDVI em relação à precipitação, para os meses de novembro de 2003 a maio de 2004 e, no final do ciclo, como se percebe, para os meses de setembro e novembro de 2004, havendo diminuição do NDVI, juntamente com a precipitação, sendo esta comparação realizada com os dados pluviométricos do mês anterior.

Observa-se, para o ponto P3, que o maior NDVI ocorreu no mês posterior àquele de maior precipitação, enquanto para os meses de novembro de 2003 a março de 2004 há incremento do NDVI em consonância com a precipitação. Uma pequena diminuição do NDVI ocorreu no mês de maio, de 0,5719 para 0,5404 , apesar do aumento na precipitação de 206,4 para 293 mm, que pode ter ocorrido por influência de nuvens, devido à cerração pouco densa e turvação atmosférica não eliminada pela CMV.

A partir de julho e com a diminuição na precipitação do mês anterior, de 585,2 mm para 97,2 e depois 25,9 mm, valores referentes aos meses de junho, agosto e outubro, respectivamente, o valor NDVI começa a decair, passando de 0,5908 para 0,4337 e depois para 0,2723 nos respectivos meses, evidenciando forte influência da precipitação do mês anterior no comportamento do NDVI para a Mata Atlântica mas, apesar da ocorrência, em junho, de uma anomalia na precipitação, com alto valor de pluviosidade, de 585,2 mm, este resultado não exerceu grande influência no aumento do NDVI.

Os gráficos do NDVI, com a precipitação do mês atual, serviram para analisar a influência da precipitação no comportamento temporal do NDVI (Figura 3). Observa-se que a precipitação ocorrida em janeiro não interferiu no valor do NDVI (P1) para este mês mas fica evidente uma influência desta precipitação para os meses seguintes (março, maio e julho); a partir do mês de julho, ocorre decréscimo no NDVI, acompanhado do decréscimo na precipitação; constatou-se, em ambos os gráficos (Figuras 2 e 3), nos meses de janeiro e julho, uma anomalia climática em relação à precipitação: a média histórica é de 81,0 e 242,6 mm, respectivamente (Koffler et al., 1986) mas, no período analisado, os valores foram de 453,4 e 585,2 mm (Tabela 1); o excesso de precipitação nesses dois meses não influenciou significativamente no valor do NDVI e, caso se realizasse uma correlação entre a precipitação e o NDVI, esses dois meses teriam que ser excluídos.

Na análise do NDVI (P2) com a precipitação do mês atual (Figura 3), nota-se que a precipitação de maio a setembro de 2004 não segue a mesma tendência do NDVI, não havendo boa relação; para o mês de janeiro, porém, a alta precipitação não influencia o valor do NDVI, permanecendo normal em relação ao desenvolvimento da cultura; a partir de janeiro, um alto acúmulo de água no solo favoreceu o crescimento fenológico da cultura, chegando a atingir valores máximos de NDVI nos meses de março e maio, enquanto no mês de julho se constatou aumento na precipitação, com redução do NDVI, em razão da colheita em 4 talhões, totalizando uma área de 29,25 ha, representando 28,88\% da área total. 


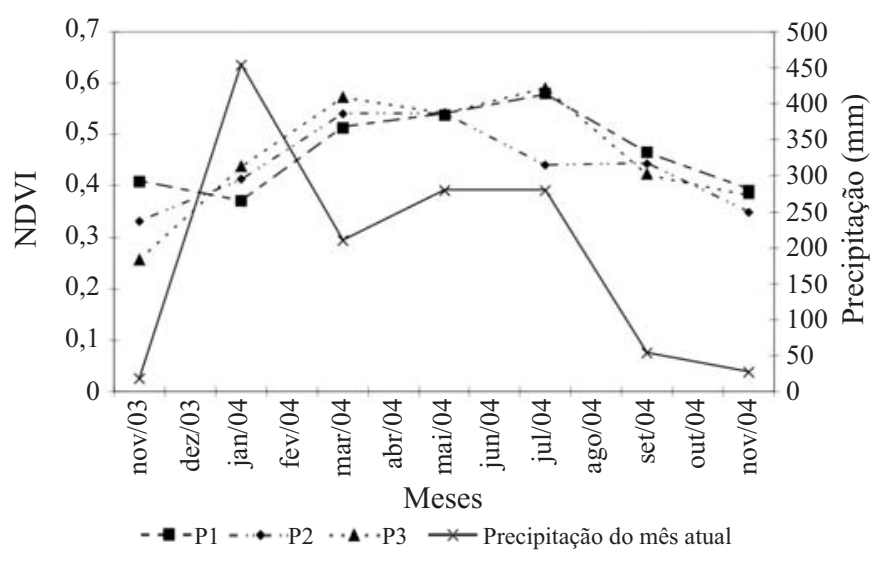

Figura 3. Gráfico do comportamento do NDVI e precipitação do mês atual para os três pontos amostrais

Observando-se o gráfico da Figura 3, referente à precipitação do mês atual, percebe-se que ocorreu, no mês de janeiro, anormalidade na precipitação, atingindo o valor de 453,4 mm, sendo que o comportamento da linha do NDVI não foi semelhante ao da precipitação desse mês, resultando que valores de precipitação fora da média histórica não têm grande influência no comportamento do NDVI (ponto P3).

A partir de março se nota comportamento semelhante da linha do NDVI e da precipitação, com exceção do mês de maio, quando ocorreu uma pequena queda no valor do NDVI, que pode ter sido devida à contaminação do pixel por nuvens.

Analisando-se as duas linhas da pluviosidade, uma referente à precipitação do mês anterior e outra à do mês atual, percebe-se que a linha da precipitação do mês anterior se assemelha melhor ao comportamento do NDVI, excluindose os meses com anomalia na pluviosidade.

Incremento e diminuição do NDVI estão associados ao aumento de densidade da biomassa, devido ao estabelecimento e desenvolvimento de culturas agrícolas, por exemplo, soja (Motta et al., 2003).

Descreve-se a relação do NDVI com o estádio fenológico da cana-de-açúcar, considerando-se que alguns autores relacionaram o NDVI com a fenologia da vegetação e sua fisiologia, concluindo que dados de satélites possibilitam a modelagem da fenologia (Moulin et al., 1996; Stöckli \& Vidale, 2004).

A Tabela 2 reúne todos os valores do NDVI, o mês correspondente e o estado do ciclo fenológico da cana-de-açúcar.
A Figura 4 apresenta uma esquematização das imagens para possibilitar uma comparação do NDVI, através das respectivas cores.

A Figura 4A representa a carta imagem do NDVI para o mês de novembro de 2003; o ponto P1 se refere ao valor de NDVI de 0,4076 e o ponto P2, de 0,3322, diferença esta perceptível na carta imagem do referido mês; o ponto P1 apresenta este valor de NDVI, em virtude de se encontrar em estádio de maturação e alguns talhões terem sido colhidos em área que totaliza 41,87 ha, representando 42,28\% da amostra; para o ponto P2, nesta mesma data, já haviam sido colhidos 96,52\% da área do pixel; portanto, o estádio fenológico ainda era inicial, deixando grande área de solo exposta; o ponto P3, centralizado em uma área de Mata Atlântica, apresentou o valor de NDVI de 0,2565, baixo para o dossel, comportamento que pode ser atribuído à influência de nuvens na aplicação da Composição de Máximo Valor, não sendo possível excluir essa influência.

Em janeiro de 2004 (Figura 4B), o valor do NDVI foi de 0,37 para o ponto $\mathrm{P} 1$, representando uma queda em relação a novembro de 2003, devido à colheita da maioria dos talhões entre outubro e dezembro de 2003 e, nesses talhões, já havia uma rebrota da cultura porém com pouca influência na resposta espectral. Com relação ao ponto P2 (Figura 4B), o NDVI indicou valor de 0,4142, representando uma média de 3 meses após a colheita, o que evidencia um aumento em relação a novembro de 2003, em que o NDVI foi de 0,3322. Esses números revelam um aumento no índice de vegetação, sempre que a cultura se desenvolve, tendo crescimento de biomassa.

Para o ponto P3 (Figura 4B), que representa um fragmento de Mata Atlântica, obteve-se um índice de 0,4394 no mês de janeiro, com uma precipitação do mês anterior de $35 \mathrm{~mm}$ e do mês atual de 453,4 mm, observando-se que a precipitação do mês janeiro não influenciou no valor do NDVI no referido mês.

O ponto P1, por outro lado, apresenta NDVI de 0,5120 e o ponto P2, 0,5404 (Figura 4C), confirmando que a cana do ponto P2 está em um estádio fenológico mais avançado que a do ponto $\mathrm{P} 1$, ou seja, com maior ganho de biomassa, sendo colhida três meses antes; referente ao ponto P1 ocorreu, em março, um aumento de 0,142 em relação ao mês de janeiro, influenciado pelo crescimento da cultura e pela precipitação dos dois meses anteriores, de $453,4 \mathrm{~mm}$, no mês de janeiro e 206,4 mm, em fevereiro.

O NDVI para o ponto P2, no mês de março, foi de 0,5404 ,

Tabela 2. Pontos analisados e ciclo da cultura

\begin{tabular}{|c|c|c|c|c|c|c|c|c|c|c|}
\hline Ponto & NDVI & $\begin{array}{l}\text { Estádio } \\
\text { Fenológico }\end{array}$ & Mês & Ponto & NDVI & $\begin{array}{c}\text { Estádio } \\
\text { Fenológico }\end{array}$ & Mês & Ponto & NDVI & Mês \\
\hline \multirow{7}{*}{ P1 } & 0,4079 & $11^{0 * \star}$ & nov/03 & \multirow{7}{*}{ P2 } & 0,3322 & $1^{0}$ & nov/03 & \multirow{7}{*}{ P3 } & 0,2565 & nov/03 \\
\hline & 0,3700 & $1^{0 *}$ & jan/04 & & 0,4142 & $3^{0}$ & jan/04 & & 0,4394 & jan/04 \\
\hline & 0,5120 & $3^{0}$ & $\mathrm{mar} / 04$ & & 0,5404 & $5^{0}$ & $\mathrm{mar} / 04$ & & 0,5719 & $\mathrm{mar} / 04$ \\
\hline & 0,5372 & $5^{0}$ & mai/04 & & 0,5372 & $7^{0}$ & mai/04 & & 0,5404 & mai/04 \\
\hline & 0,5801 & $7^{0}$ & jul/04 & & 0,4406 & $9^{\circ}$ & jul/04 & & 0,5908 & jul/04 \\
\hline & 0,4647 & $9^{0}$ & set/04 & & 0,4426 & $11^{0 * *}$ & set/04 & & 0,4237 & set/04 \\
\hline & 0,3921 & $11^{0 * *}$ & nov/04 & & 0,3489 & $\star \star \star$ & nov/04 & & 0,3862 & nov/04 \\
\hline
\end{tabular}

* Mês após a colheita; ** Colheita; *** Outro ciclo 


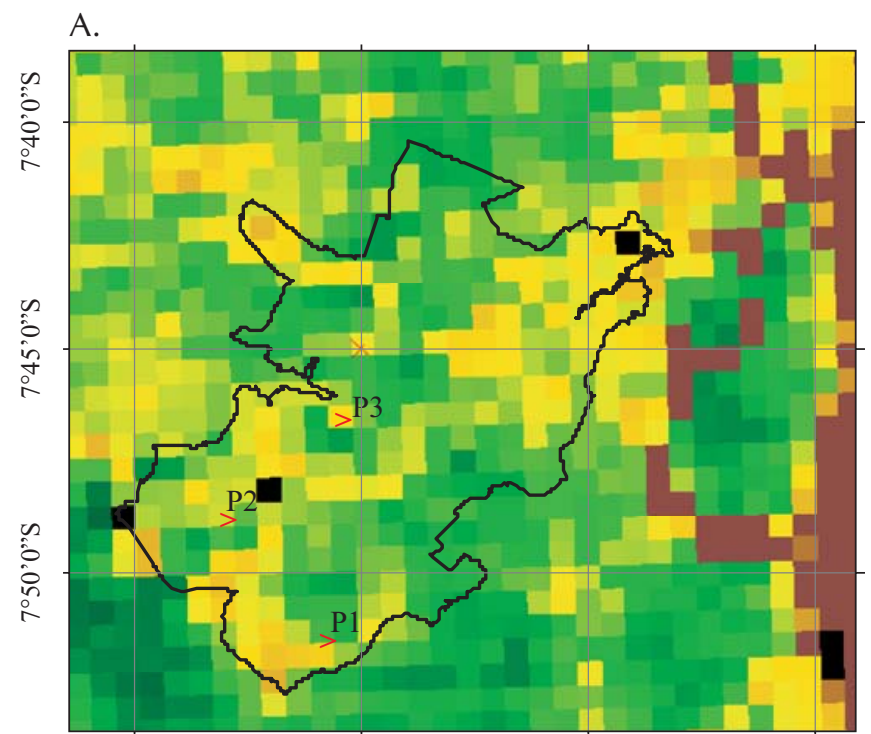

C.

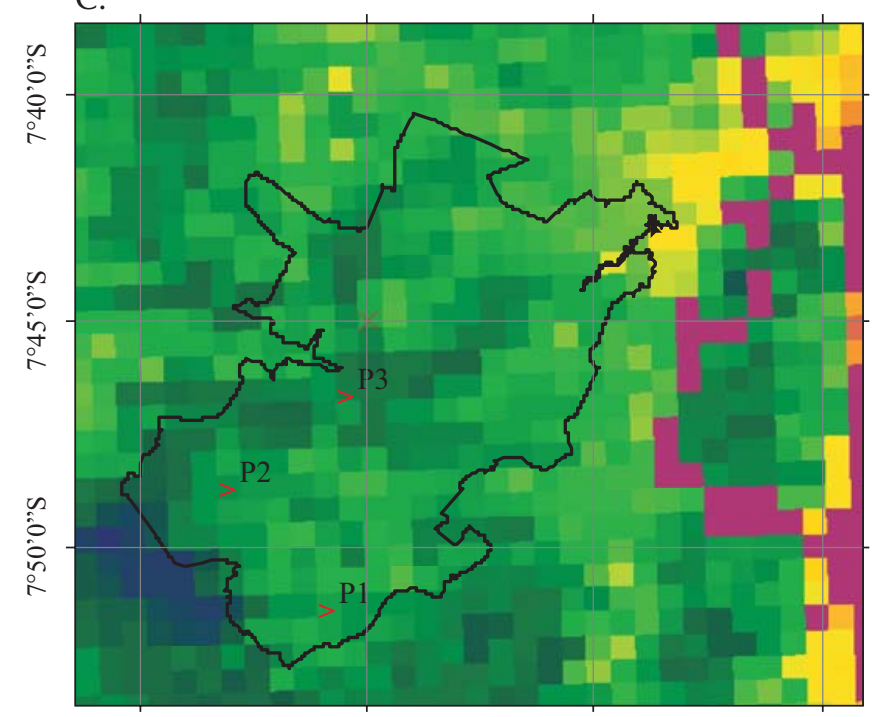

E.

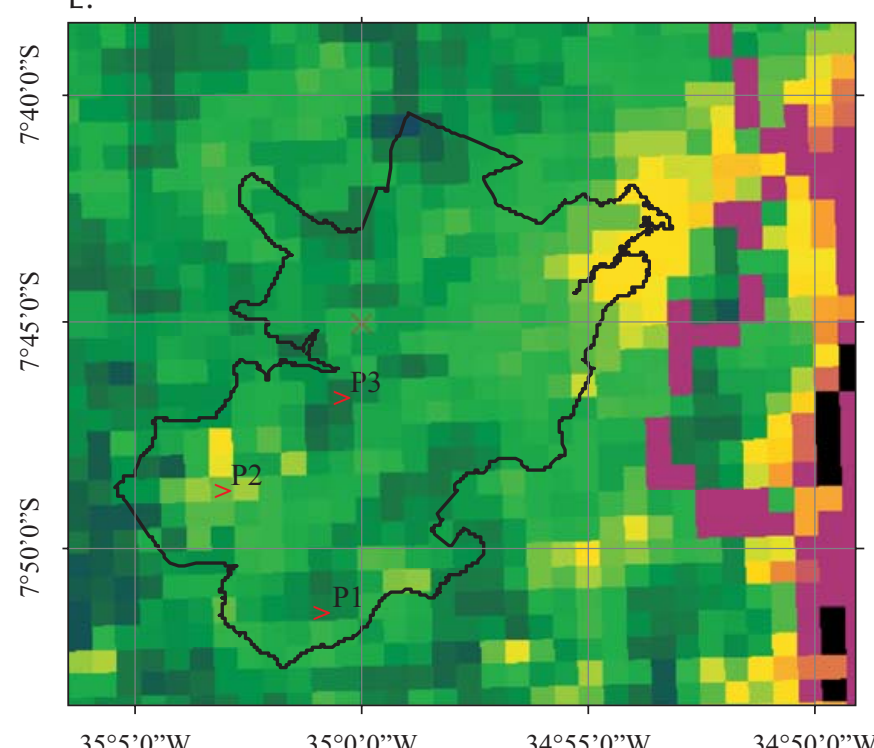

B.

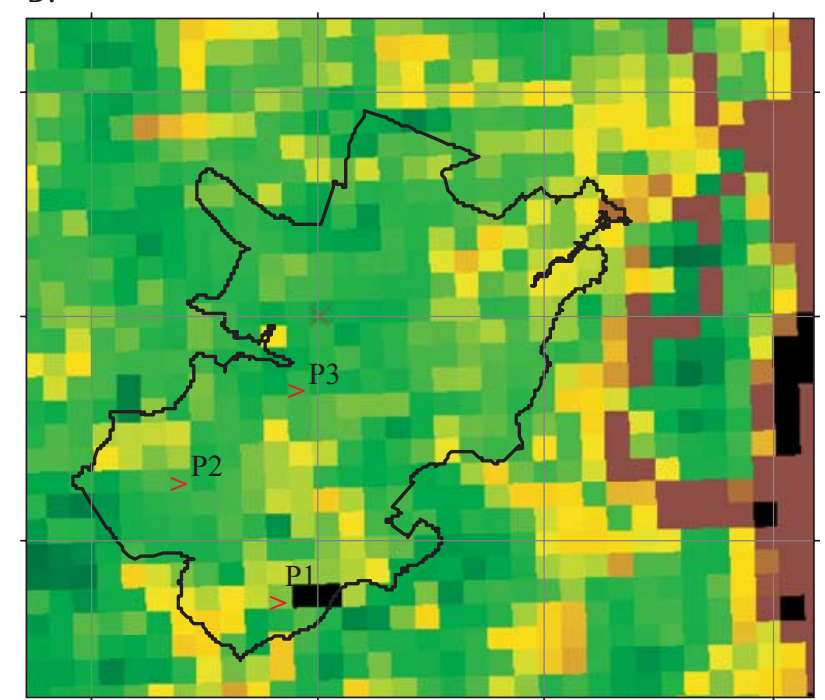

D.

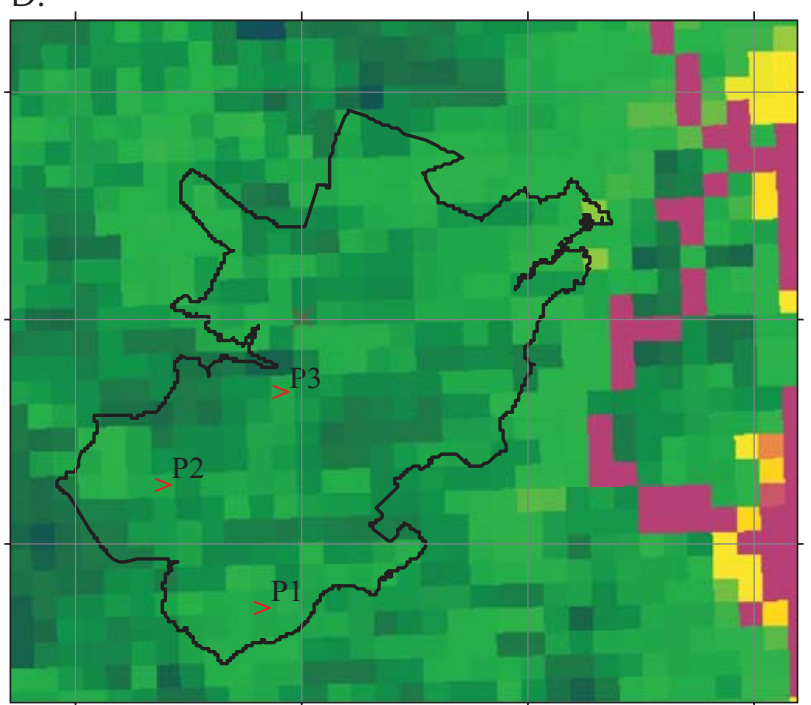

F.

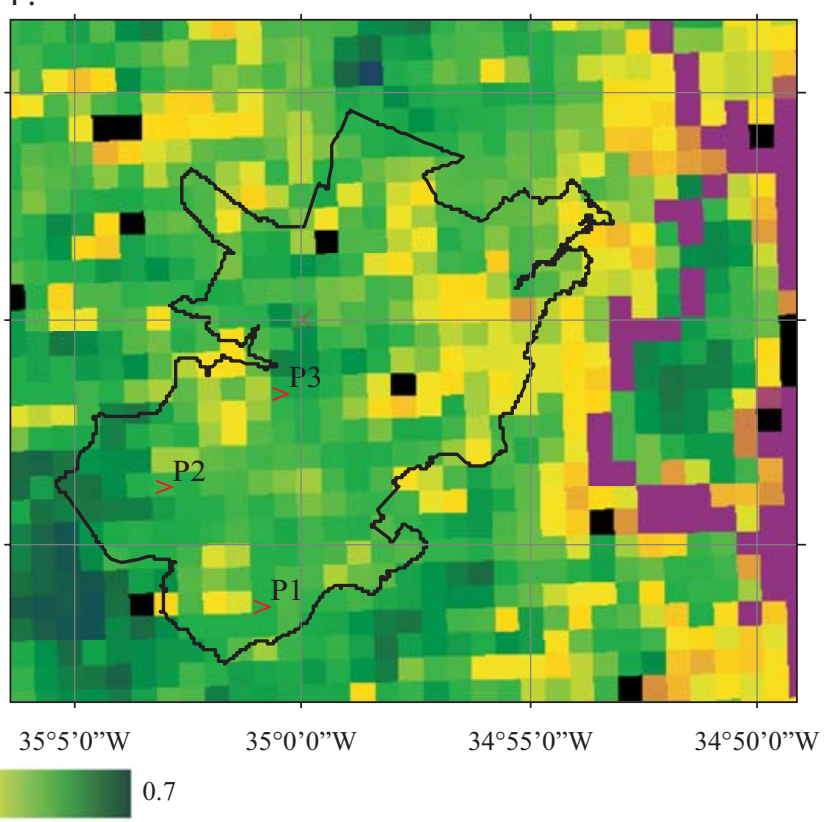

Figura 4. Esquematização das cartas-imagem para os meses de: novembro de 2003 : $A$; janeiro: $B$, março: C, maio: $D$, julho: E e setembro de $2004: F$

R. Bras. Eng. Agríc. Ambiental, v.11, n.6, p.607-614, 2007. 
com um aumento de 0,1262 em relação ao valor do índice no mês de janeiro, de 0,4142 , sendo que, em janeiro, a idade da cultura era de 3 meses e, em março, de 5 meses.

Como evidenciado na Figura 4C, o ponto P3 mostra valor de NDVI de 0,5719, com aumento de 0,1325 em relação ao mês de janeiro; este aumento foi influenciado pela precipitação anterior ao mês de março, de 206,4 mm, e do mês atual, 209,9 mm.

Na carta-imagem do mês de maio (Figura 4D), os pontos P1 e P2 se apresentam semelhantes, com NDVI de 0,5372, comportamento que pode evidenciar que esses dois estádios fenológicos se assemelham em relação ao NDVI, sendo necessário um estudo mais detalhado para uma comparação melhor. No ponto P1, quanto ao mês anterior, houve um ligeiro aumento, passando de 0,5120 para 0,5372 destacando-se, com esta variação, um aumento da biomassa (Fontana et al., 2001). A precipitação para o mês anterior a março foi de 206,4 mm e, para a anterior a maio, de $293 \mathrm{~mm}$, tendo pouca influência na variação do NDVI.

Conforme observado na Figura 4D, o ponto P2 apresentou NDVI de 0,5372, com ligeira diminuição em relação ao mês de março, de 0,5404; a partir daí, o NDVI começa a decair, pois neste período a cultura se encontra com sete meses após o corte e 70,75 ha estão entrando em processo de maturação, em que ocorre acúmulo de sacarose; nesta fase se dá, também, o valor máximo de área foliar (Casagrande, 1991), indicando um crescimento lento.

Para o ponto P3, o NDVI apresentou valor de 0,5404, ocorrendo ligeira diminuição em relação ao valor anterior, de 0,0315 .

A Figura 4E representa a carta imagem para o mês de julho, ressaltando-se que o ponto P1 teve valor de NDVI de 0,5801 atingindo, no mês, o valor máximo alcançado durante todo o ciclo da cultura, um aumento em relação ao mês anterior, de 0,0571 e, nesta época, o NDVI esteve próximo a valores de NDVI para o ponto P3, que representa a Mata Atlântica; a partir deste mês, o NDVI começa a diminuir indicando o início do processo de maturação, a partir dos 7 meses, quando se inicia o acúmulo de sacarose; o ponto P1 apresenta NDVI maior que o P2, em virtude do último se encontrar em um estádio mais avançado de maturação.

O NDVI para o ponto P2 foi de 0,4406, com redução de 0,0966 em relação ao mês anterior analisado, cujo valor foi de 0,5372 , evidenciando um avanço na maturação e diminuição no acúmulo de biomassa; esta diminuição no NDVI não acompanhou o comportamento da precipitação, que passou de 293 para 585,2 mm no mês anterior a julho, indicando que não influencia o comportamento do NDVI nesse estágio de desenvolvimento da cultura.

Com relação ao ponto P3, o valor do NDVI foi de 0,5908 para o mês de julho, conforme está expresso na Figura 4E, havendo um aumento de 0,0504 em relação ao mês anterior analisado, indicando que a precipitação exerce pequena influência no comportamento da Mata Atlântica quando comparado com a cultura da cana no estádio de maturação. Os valores de precipitação foram de 585,2 mm para o mês anterior a julho e de $293 \mathrm{~mm}$ para o mês anterior a maio, sen- do que o NDVI da Mata Atlântica aumentou e o da cana em estágio de maturação (P2) diminuiu.

Na carta-imagem do mês de setembro (Figura 4F), o P1 apresentou NDVI maior que o P2, considerando-se que o último se encontrava em estágio de maturação mais avançado, próximo à época de colheita, e 29,25 ha já haviam sido colhidos. Na carta-imagem se observa, no ponto P1, o mesmo que aconteceu com o P2, ou seja, a partir do sétimo mês o NDVI começa a diminuir até o mês de novembro, indicando o início da maturação, como fica evidenciado nos valores em seqüência a seguir:

O ponto P1 passou de 0,5801 no mês de julho, para 0,4647, no mês de setembro e 0,3929 em novembro.

No ponto P2 o NDVI passou de 0,5372 no mês de maio, para 0,4406 em julho, 0,4426 em setembro e 0,3489 em novembro. Observa-se, também, que a precipitação diminuiu, contribuindo para a queda do NDVI.

Verifica-se, ainda, uma diminuição do NDVI para o ponto P3, nos meses de setembro e novembro, obtendo-se os valores de 0,4237 e 0,3862, respectivamente, e se destacando que esta época corresponde ao período de pouca precipitação, com valores de 97,2 mm para o mês de agosto, de $53,8 \mathrm{~mm}$ em setembro, de 25,92 $\mathrm{mm}$ em outubro e de $26,7 \mathrm{~mm}$, em novembro.

\section{CONCLUSÕES}

1. É possível acompanhar variações fenológicas da cultura da cana-de-açúcar com imagens do NOAA, em virtude da alta resolução temporal, apesar da sua baixa resolução espacial.

2. A anomalia na precipitação, tal como ocorreu nos meses de janeiro e julho, não exerceu grande influência no comportamento da cultura da cana-de-açúcar, verificando-se o mesmo em relação à Mata Atlântica.

3. No início do ciclo da cultura, no intervalo de 1 a 2 meses, não é possível distinguir diferenças fenológicas através do NDVI.

4. O uso de imagens de baixa resolução espacial teria melhores resultados se houvesse uniformidade na data de corte e plantio dos talhões que compõem cada amostra da cana-de-açúcar.

5. Satélites de alta resolução temporal possibilitam o melhor acompanhamento para culturas agrícolas anuais como, por exemplo, a cana-de-açúcar, nas regiões litorâneas e na Zona da Mata, em que existe alta quantidade de nuvens, uma vez que registra grande quantidade de imagens e, também, porque a Composição de Máximo Valor permite a elaboração de mosaicos, reduzindo a interferência de nuvens.

6. A partir do sétimo mês do ciclo da cultura o NDVI começa a cair, coincidindo com o início da maturação, fato observado também nos dois pontos amostrais da cana-deaçúcar.

7. No mês de julho, que representa o sexto mês do ciclo da cultura, o NDVI apresentou o máximo valor para o ponto P1, ficando próximo ao da Mata Atlântica; para o ponto P2, não ocorreu um NDVI próximo ao da Mata Atlântica, 
haja vista que alguns talhões estavam em ciclos diferentes de desenvolvimento.

8. O comportamento da curva do NDVI para a Mata Atlântica, no intervalo do ciclo da cana-de-açúcar analisado, foi semelhante no início, no meio e no fim do ciclo porém com valores de NDVI diferentes, indicando correlação com a precipitação.

\section{LITERATURA CITADA}

Barbosa, H. A. Análise espaço temporal de índice de vegetação AVHRR/NOAA e precipitação na região Nordeste do Brasil, em 1982-85. São José dos Campos: INPE, 1998. 164p. Dissertação Mestrado

Casagrande, A. A. Tópicos de morfologia e fisiologia da cana-deaçúcar. Jaboticabal: FUNEP. 1991. 157p.

Ferreira, N. S. Aplicações ambientais brasileiras dos satélites NOAA e TIROS-N. São Paulo: Oficina de textos, 2004. 271p.

Fontana, D. C.; Weber, E.; Ducati, J.; Figueiredo, D. C.; Berlato, M. A.; Bergamaschi, H. Previsão da safra de soja no Brasil: 1999/2000. In: Congresso Brasileiro de Agrometeorologia, 12, 2001, Fortaleza. Anais... São Paulo: SBA, 2001. v.2. p.585-586.

Fortes, Caio. Discriminação varietal e estimativa de produtividade agroindustrial de cana-de-açúcar pelo sensor orbital ETM+/ LANDSAT. Piracicaba: 2003. 131p. Dissertação Mestrado

Goward, S. N.; Tucker, C.; Dye, D. G. North American vegetation patterns observed with the nimbus-7 advanced very high resolution radiometer. Vegetation, v.64, p.3-14, 1985.
Kaufman, Y. J.; Holben, B. N. Calibration of the AVHRR visible and near-IR bands by atmospheric scattering, ocean glint and desert reflection. Interantional Journal of Remote Sensing, London, v.14, n.1, p.21-52, 1993.

Koffler, N. P.; Lima, J. F. W. F.; Lacerda, J. F.; Santana, J. F; Silva, M. A. Caracterização edafo-climática das regiões canavieiras do Brasil: Pernambuco. Programa nacional de melhoramento da cana-de-açúcar. Piracicaba: PLANALSUCAR, 1986. 78p.

Motta, J. L. G.; Fontana, D. C.; Weber, L. Análise da evolução temporal do NDVI/NOAA em Região de Soja no Rio Grande do Sul. In: Simpósio Brasileiro de Sensoriamento Remoto, 11, 2003, Belo Horizonte. Anais... Belo Horizonte: INPE, 2003. p.197-204.

Moulin, S.; Kergoat, L.; Viovy, N.; Dedieu, G. Global-Scale assessment of vegetation phenology using NOAA/AVHRR satellite measurements. Journal of Climate, Boston, v.10, n.6, p.1154-1170, 1996.

Pontes, P. P. B.; Rocha, J. V.; Lamparelli, R. A. C. Análise temporal de índices de vegetação como subsídio à previsão de safra de cana-de-açúcar. In: Simpósio Brasileiro de Sensoriamento Remoto, 12, 2005, Goiana. Anais... Goiania: INPE, 2005. p.217-224.

Stöckli, R.; Vidale, P. L. European plant phenology and climate as seen in a 20 years AVHRR land-surface parameter dataset. International Journal of Remote Sensing, London, v.25, n.17. p.3303-3330, 2004.

Tanré, D.; Holben, B. N.; Kaufman, J. Y. Atmospheric correction against algorithm for NOAA-AVHRR products: Theory and application. IEEE Transactions on Geoscience and Remote Sensing, New York, v.30, n.2, p.231-248, 1992. 